\title{
Computerized High-tech Detection Technology of Immunofluorescence Labelled Waterborne Pathogenic Bacteria
}

\author{
CATALINA STOICA ${ }^{1 \#,}$ PAUL NICOLAE ANCUTA ${ }^{2 \#, ~ I R I N A ~ E U G E N I A ~ L U C A C I U ~}{ }^{1}$, ALINA ROXANA BANCIU1, SORIN SOREA², \\ ANCA ATANASESCU², MIHAI NITA LAZAR ${ }^{1 *}$ \\ ${ }^{1}$ National Research and Development Institute for Industrial Ecology-ECOIND, 71-72 Drumul Podu Dambovitei, 060652, Bucharest, \\ Romania \\ ${ }^{2}$ National Institute of Research and Development in Mechatronics and Measurement Technique, 6-8 Pantelimon Str., Bucharest, \\ Romania
}

\begin{abstract}
The waterborne pathogenic bacteria, especially the enteric bacteria of human fecal origin, have become currently a global public health issue. The detection and quantification of drinking water microorganisms have been an essential part of any quality control or water safety management plan interconnected to enteric bacterial pathogens such as Salmonella spp., Shigella spp., Vibrio cholerae or to non-faecal bacterial pathogens such as Pseudomonas aeruginosa. The standard methods of detecting waterborne pathogenic bacteria are time-consuming due to the bacterial growing step in a specific culture media, followed by isolation, microbiological and/or serological identiûcation and in some cases followed by subspeciûc characterization. This studyaimed to develop a faster, powerful, more sensitive and reproducible diagnostic tool to monitor a specific pathogen contamination in drinking water (Pseudomonas aeruginosa) by specific antibody-antigen interactions followed by a computerized technology to identify bacteria as a digital image from water samples. Digital Image processing was carried out using National Instruments Vision Assistant Software. Pseudomonas aeruginosa was specifically detected by immunofluorescence technique with fluorophore tagged antibodies, and then the image formation in fluorescence microscopy was processed by computer vision software functions organized in pipeline-like data analysis processing. Overall, these techniques proved to be a reliable one, time-effective and sensitive for diagnosis and prevention of drinking water quality and waterborne bacterial disease.
\end{abstract}

Keywords: antibody-antigen interaction, bacteria, immunofluorescence, high-tech technology

Contaminated or poor sanitation water have been linked to transmission of diseases such as cholera, diarrhea, dysentery, hepatitis A, typhoid and other respiratory issues [1-3]. Moreover, those risks have been kept high byabsent, inadequate or inappropriately water management and/or sanitation services exposing individuals to health risks which could normally be preventable by a proper management. World Health Organization (WHO) leads global efforts to prevent transmission of waterborne disease, thus it recommends water safety plans (WSPs) as the most effective approach for consistently ensuring the safety of a drinking-water supply, because this approach manages the risk from the catchment or water sources to the consumer's tap $[4,5]$. The microbial contamination have induced major health consequences, so the European Union (Council Directive 98/83/EC and Directive (EU) 2015/ 1787) issued a drinking water policy ensuring that water intended for human consumption can be consumed safely on a life-long basis and this represents a high level of health protection [6]. The quality of drinking water from Romania is regulated by Law 458/2002 (republished in 2011 and amended by the Norm 22/2017), that involves monitoring the microbiological as well as chemical parameters. Among microbiological parameters, there are two categories of hygienically relevant microorganisms: a) pathogenic microorganisms associated with water related illness and outbreaks [ 7] and b) index bacteria indicating the presence of pathogenic organisms of fecal origin [8].

A strategy practiced for decades as a gold standard in the assessment of microbial safety of drinking water was based on the culture dependentenumeration and detection of fecal indicator bacteria, such as total coliforms, Escherichia coli (E. coli), and enterococci [9]. Due to the fact that drinking water safety is not related particularly to faecal contamination, and some microorganisms, such as Legionella sp. and Pseudomonas aeruginosa ( $P$. aeruginosa) grow in piped water distribution systems, the regulations governing bottled water quality entails the analysis of gram-negative $P$. aeruginosa [10] as an indicator of sanitary condition. It has been stated that this rod-shaped heterotrophic bacteria is resistant to water disinfection processes using chlorine, chloramines, ozone, or iodine [11]. In addition, its ability to form or join biofilms makes ot even harder to remove it even at concentration of $600 \mathrm{mg} \mathrm{Cl} / \mathrm{l}$ [12]. Moreover, bacterial biological models exploited their high degree of resistence to various chemical compound from pollutants to the pharmaceutical compounds [13-15].

Bacterial identification and quantification in water samples (bottled water, pool waters and waters intended for human consumption) have been of great importance in order to detect the emerging risks [16]. The standard method including bacterial growth in culture media after isolation by membrane filtration is sensitive, practical and cost-effective, but often laborious and time-consuming requiring days of work to get the results of the test [17]. The speed of providing microbiological results is essential when the health population is in balance facing a possible outbreak. Therefore, rapid alternative methods such as nucleic-acid based, biosensor-based and immunologybased have been described for detection of waterborne pathogenic bacteria [18]. 
In the past few years, nucleic acid-based technology achieved widespread use in the field of pathogen detection, with a particular focus in polymerase chain reaction (PCR) assays developed mainly to detect every relevant bacterial pathogen [19] based on recognition of specific nucleotide (DNA or RNA) sequences of microorganisms. Currently, quantitative PCR (qPCR) is widely available and provides as good as or better sensitivity for the detection of molecular targets than all other currently available detection strategies, including newly developed assays such as: microarrays and prosequencing [20-23]. Furthermore, modern advances in micro- and nanofabrication technology have led to the development of a wide range of nucleic-acid based biosensors that capitalize on the new capabilities of microfluidic technologies and micro total analysis systems in order to reduce reagent and power consumption, enhance analytical performance, and enable portability. Many of these technologies have been extensively studied [17, 18, 24-26], successfully commercialized, and are currently widely used in clinical and research laboratories. In today's world, the genetically engineered whole cell-based bacteria have usually utilized to generate and amplify the luminescence signal. Bacteria incorporate reporter genes that code for signaling elements that emit bioluminescent, fluorescent, or colorimetric endpoints [27-31]. Moreover, bacteria have a great membrane structural diversity which is encompassed in one membrane (gram-positive bacteria) or in two inner and outer membranes (gram-negative bacteria). This membrane structural diversity translates to a multitude of molecule with an antigenic potential, thus antibodies raised against those specific bacterial molecules [32] could be used as a immunological diagnostic tools in medical and/ or environmental fields due to their high specificity, reliability and accuracy. There have been many ways to detect the interaction between antibody and bacteria, but among them, the immunofluorescence detection based on the fluorochome tagged antibody have been one of the most straight one [25]. The bacterial detection image formation in fluorescence microscopy could be processed and be switch to a digital signal which could be wireless sent to health and/or environmental monitoring specialized organization, in order to rapidly prevent any potential bacterial outbreaks. The image processing has been carried out using NI Vision Assistant Software [33] which is based on pipeline type. The fluorescence digital image is composed of three channels in RGB color space (alpha channel not used) and the digital image could be obtained through a pipeline type.

In this paper, we described an immunofluorescent fast, specific and reliable alternative bacterial detection method to the classical and laborious bacterial identification method based on repeatedly bacterial growth on selective medium. A gram-negative bacterium $P$. aeruginosa with a pathogenic potential was specifically immunofluorescent detected and the immunofluorescent image was processed, digitalized and wireless sent to organizations involved in health and environmental monitoring.

\section{Experimental part}

Bacterial growth. The bacterial strains $P$. aeruginosa (ATCC 27853) and Enteroccocus faecalis (E. faecalis)
(ATCC 29212) were purchased from ATCC (International Center for the Authentication, Storage and Production of Microorganisms and Cell Lines). The strains were grown on tryptone soya agar (Oxoid, UK) and incubated overnight $(\mathrm{O} / \mathrm{N})$ at $37^{\circ} \mathrm{C}$. One colony was then transferred in $5 \mathrm{ml}$ acetamide nutrient broth ( $P$. aeruginosa) or sodium azide broth ( $E$. faecalis) in a shaking incubator (New Brunswick Scientific, Innova 44 ) at $37^{\circ} \mathrm{C}$ for $24 \mathrm{~h}$. Bacterial growth was monitored by measuring the absorbance at $600 \mathrm{~nm}$ using UV-Vis spectrometer (VWR International, USA).

Bacterial immunofluorescence detection. The 0.4 $O D_{600 n m}$ bacterial suspension in $250 \mu \mathrm{L}$ PBS was incubated $O / N^{600 n m}$ at $4^{\circ} \mathrm{C}$ in presence of monoclonal antibody anti-P. aeruginosa tagged with Alexa Fluor 647 (Novus Biologicals, CO, USA) (dilution of $1: 100$ ). After the incubation, the sample was centrifuged for 5 minutes at $5000 \mathrm{rpm}$ and 4 ${ }^{\circ} \mathrm{C}$, and the bacterial pellet was washed trice in PBS. The bacterial sample was resuspended in $20 \mu \mathrm{L}$ mounting medium for further microscopic analysis. The microscopic detection of fluorescent bacteria was performed using LEIKA DMi8 inverted microscope at a 63X magnification. The sample was observed in both fluorescence and transmitted light and the negative control consisted on $P$. aeruginosa incubated in absence of monoclonal antibody anti-P. aeruginosa tagged with Alexa Fluor 647 or on $E$. faecalis incubated in presence of antibody anti- $P$. aeruginosa.

Computerized analysis and measurement of pathogenic bacteria. Computerized analysis was carried on immunofluorescence digital images obtained by standard microscopic investigations. The computerized analysis consisted of a pipeline processing image based on two stages: i) creating the binary mask (fig. 1) and ii) bacteria identification the in bright field microscopic image.

The image processing flow of the binary mask creation was described below:

Step \#0: The fluorescence image was loaded from disk into the NI Vision Assistant Software application.

Step \# 1: Calibration by associating a numerical value of microns to a numerical value of a distance expressed in pixels [34].

Step \#2: The red color plane was extracted from the fluorescence image.

Step \#3: The image histogram was displayed onscreen.

Step \#4: A threshold was applied on grey level in order to obtain a binary image. That was the most important computation step. Two approaches were used: global threshold and local threshold. Global threshold enforced a unique threshold value over the entire image. Local threshold took into consideration a user defined neighborhood around each pixel in image. That rectangular windows is moved over the entire image.

Local Mean value and variance of a image contained in a neighborhood of $\mathrm{MxN}$ size were:

$$
\begin{aligned}
& \mathrm{m}=\frac{1}{M^{*} N} \sum_{i=0}^{M-1} \sum_{j=0}^{N-1} I(i, j) \\
& \sigma^{2}=\frac{1}{M^{*} N} \sum_{i=0}^{M-1} \sum_{j=0}^{N-1}[I(i, j)-m]^{2}
\end{aligned}
$$

In addition, Niblack algorithm $[35,36]$ was used on the threshold calculus, where:

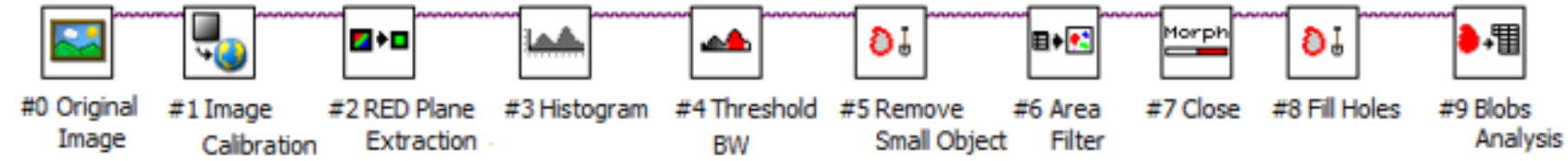

Fig.1. Pipeline processing for obtaining image mask and blobs' data analysis 
Threshold $(i, j)=m(i, j)+k^{*} \sigma(i, j)$ where $k \in[0 . .1]$

If I $(i, j)>$ Threshold $(i, j)$

then I(i,j) belongs to an object (particle)

else $\mathrm{I}(\mathrm{i}, \mathrm{j})$ belongs to the background.

Step \#5: Remove small objects. This morphological operation was used to eliminate some particles using one iteration of $3 \times 3$ erosions. The remaining particles had exactly the same shape as in the immunofluorescent source image.

Step \#6: Particles removing was continued by imposing a minimum area value.

Step \#7: The binary image was dilated, then eroded. The effect was compacting the scattered pixels and maintaining the overall shape of particles.

Step \#8: Pixels belonging to inner bacterial areas were assigned white color.

At this step,the binary image contained white blobs (bacterial areas), firmly demarcated from background .

Step \#9: Every blobs ( bacterial areas) got an unique ID. The numerical values of the selected bacterial areas were displayed in a form table (table 2).

The antibody targeted bacteria was also identified the in bright field by superimposing the digital masked fluorescent image on the bright image.

\section{Results and discussions}

Specific bacterial detection with fluorescent tagged antibody. One colony from each bacterial strain isolated from the solid growth medium was incubated in specific broth and both bacterial strains ( $E$. faecalis and $P$. aeruginosa) showed a robust growth curve after about 3 hours on incubation at $37^{\circ} \mathrm{C}$ reaching a high optical density up to $1.50 \mathrm{D}$ measured at $600 \mathrm{~nm}$ (table 1).

A bacterial density of $0.4 O_{600 m}$ was incubated in presence or absence of an monoclonal antibody anti-P. aeruginosa tagged with Alexa Fluor 647. The results were analyzed by microscopy in transmitted lightand also in the fluorescence. The bright images (obtained in the transmitted light) showed an even repartition of the
Table 1

BACTERIAL GROWTH

\begin{tabular}{|c|c|c|}
\hline Bacterial strain & Growth medium & $\begin{array}{c}\text { Absorbance } \\
\text { at } 600 \mathbf{~ n m}\end{array}$ \\
\hline E. faecalis & $\begin{array}{c}\text { Broth medium - simple } \\
\text { concentrated sodium azide }\end{array}$ & 1.250 \\
\hline P.aeruginosa & Acetamide nutrient broth & 1.500 \\
\hline
\end{tabular}

bacteria regardless if it was the bacterial strain used as a negative control ( $E$. faecalis) or the bacterial strain of interest ( $P$. aeruginosa) (fig. 2$)$. The shaped identified in the bright field were consistent with the shapes of each bacterial strain used in this test.

The fluorescent analysis of those bacterial strains incubated in the presence of the monoclonal antibody antiP.aeruginosa tagged with Alexa Fluor revealed the specificity of those antibody to the P.aeruginosa strains (fig. 3). No detection (red spots) were detected in the $E$. faecalis bacterial sample, but an abundant red spots presence on the P.aeruginosa strain. This showed a very robust and specific interaction between the antibody and the targeted bacteria. The red spots, observed in the fluorescent image, seemed to overlap to the bacterial shapes identified in the transmitted light (bright field) which suggested an even interaction all over the membrane surface between antibody and targeted bacterial molecule (antigenic properties) from the bacterial surface.

\section{Processing of the bacteria immunodetection forming image into a digital signal}

Both brightfield and fluorescence images were processed by a pipeline processing protocol (fig. 1) in order to achieve a fast and specific digital signal linked to the bacterial identification.

Initially, the fluorescent image of the P.aeruginosa strain was processed to obtaine a grey level image which contains just one plane by extracting the $\mathrm{R}$ (red) channel. A binary digital image was obtained by applying a threshold value to the grey level image (pixels' values spread in 0.255 domain), having background (black) and foreground
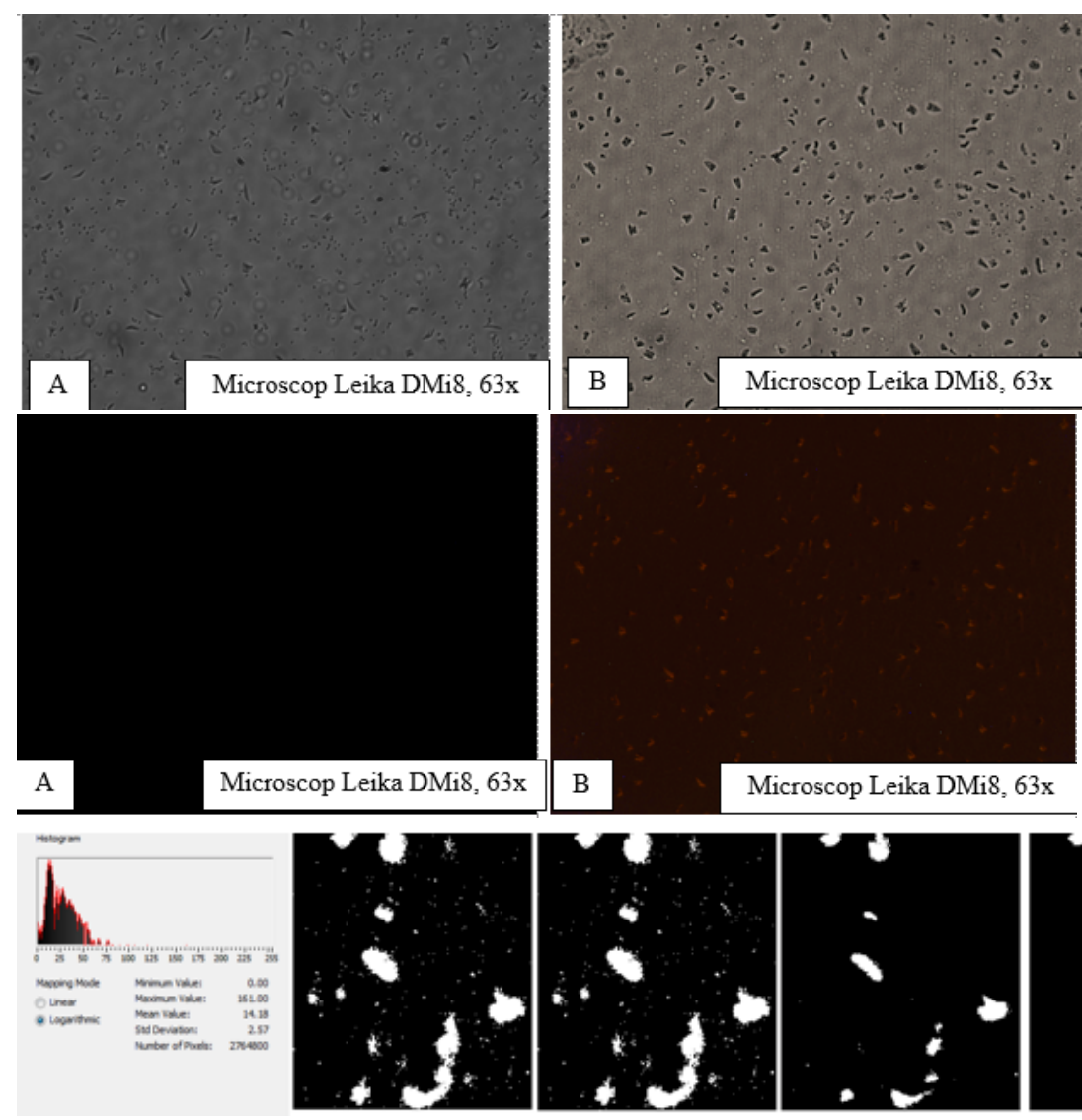

http://www.revistadechimie.ro

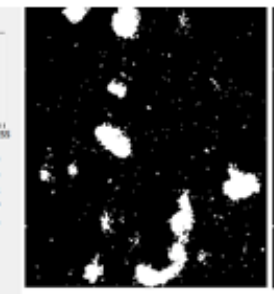

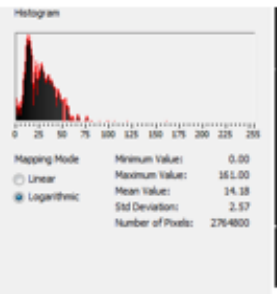

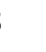

Fig. 2. Microscopic analysis in transmitted light (bright field) of bacterial strains (63x magnification): A-E. faecalis, negative control; B-P. aeruginosa

Fig. 3. Microscopic analysis in fluorescence of bacterial strains: A-E. faecalis, negative control

(red filter, $635 \mathrm{~nm}$ ); B-P. aeruginosa (63x magnification)

Fig. 4. Threshold modification of a grey level image after extracting the red of the in the original fluorescence image. 

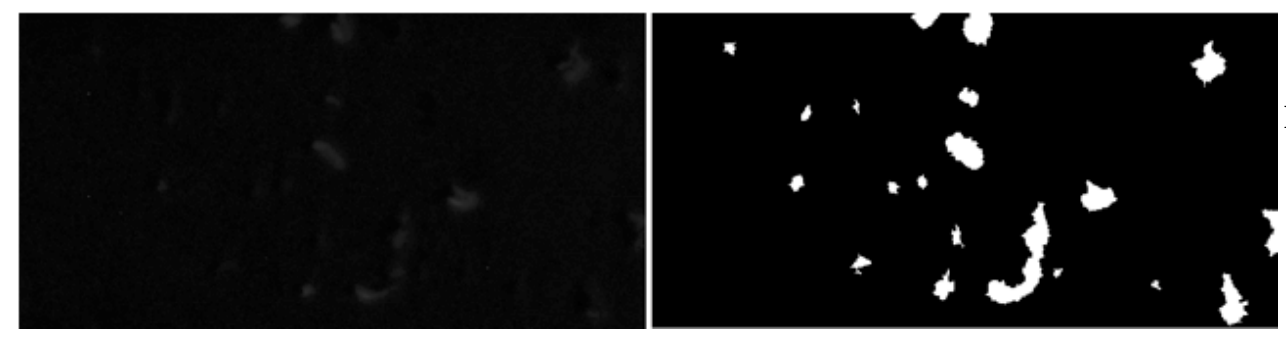

Fig. 5. Digital image processing of the greyscale image $(A)$, using Niblack thresholding (B)

Table 2

BLOB (BACTERIAL AREAS) REPORT

\begin{tabular}{|c|c|c|c|c|c|c|c|c|c|c|c|c|}
\hline Resul's & 5 & 6 & 12 & \begin{tabular}{|l|l|} 
& 14 \\
\end{tabular} & \begin{tabular}{|l|l|}
$\ldots$ & 17 \\
\end{tabular} & $\ldots \mid 26$ & $\ldots 20$ & $\ldots .31$ & \begin{tabular}{|l|l|}
$\ldots$ & 34 \\
\end{tabular} & $\ldots$ & 40 & 41 \\
\hline Area & 384,00000 & 839,00000 & 1156,00000 & \begin{tabular}{|l|l|} 
& 104,00000 \\
\end{tabular} & \begin{tabular}{|l|l|} 
& 331.00000 \\
\end{tabular} & \begin{tabular}{|l|l|} 
& 254,00000 \\
\end{tabular} & 50,00000 & \begin{tabular}{l|l} 
& 105,00000 \\
\end{tabular} & \begin{tabular}{l|l}
1 & 928,00000 \\
\end{tabular} & 0 & 161,00000 & 96,00000 \\
\hline Area Calorated & 384,00000 & 899,000000 & 1156,00000 & 104.00000 & 331.00000 & 254,00000 & 50,00000 & 105,00000 & 928,00000 & p & 161.00000 & 96,00000 \\
\hline Ya Area/Image Area & 0.01399 & 0.03035 & 0.04181 & 0,00376 & 0.01197 & 0.00919 & 0.00181 & 0.00380 & 0.03356 & & 0.00582 & 0.00347 \\
\hline
\end{tabular}

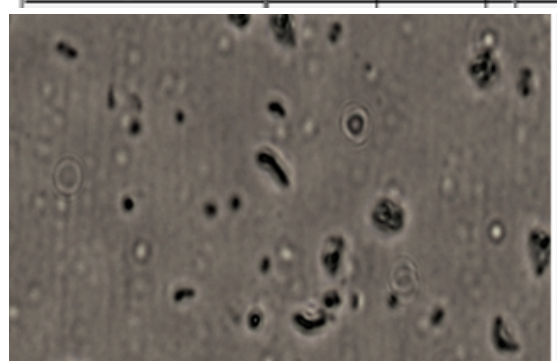

(white) (fig. 4). A good criteria for threshold value is to choose a local minima in the histogram.

The binary digital image was further enhanced by several morphological filters and it was carried out for foreground area, in order to eliminate the noise [37]. For small window width and height, Niblack criteria worked well around compact group of pixels, but produces artefacts between those groups, as expected. In order to obtain good results when applied to the whole image, a sliding window having dimension a fourth of the image size was chosen and $\mathrm{k}=1$.Background correction (BCG) worked well on sliding windows having also lesser dimensions (fig. 5). An immediate conclusion is the following: the existence of blobs in the image involves the presence of analyzed bacteria in the bright image.

At the end, a proper binary image was obtained, containing compact blobs (bacterial areas) where fluorescence markers have been detected. The binary digital picture was used for measuring the areas of the detected blobs (bacterial areas) (table 2).

This table containing area of each bacterial areas (expressed both in pixels and square microns) and the percent of each blob area/image area was automatically generated. The sum of blob areas relative to the whole image area gives a percentage indicator of the presence of bacteria in the whole bright image.

The overlapping of the masking bright image with the binary mask image only showed the bacteria recognized by the antibodies eliminating the contaminants and other bacteria which are not specifically recognized by immunofluorescence (fig. 6).

When masked bright image is saved to file, masked area are saved unchanged while blue area are turn to black. This new digital image contains information related only to specific studied bacteria. Figures 5 and 6 , as well as the results of the blobs in figure 4 were information on which the final report on the microbiological quality of the analyzed water sample are based on.

\section{Conclusions}

A specific and rapid identification of $P$. aeruginosa strains from water sample was performed by immunofluorescence in presence of monoclonal antibody anti-P.
Fig. 6. Bacterial identification by specific immunofluorescence. A) original bright image of the initial water sample; B) overlapping of the masking bright image with the binary mask image 
14. GHEORGHE, S., PETRE, J., LUCACIU, I., STOICA C., NITA-LAZAR, M., Environ. Monit. Assess., 188, 2016, p. 379

15. BANCIU, A. (CATRANGIU), NICULESCU, D., NITA-LAZAR, M., LUCACIU, I., STOICA C., MIHAESCU, G., J. Environ. Prot. Ecol., 17, 2016, p. 127

16. STOICA, C., VASILE, G.G., BANCIU, A., NICULESCU, D., LUCACIU, I., NITA LAZAR, M., Rev. Chim. (Bucharest), 68, no.8, 2017, p. 1744 17. LOPEZ-CAMPOS, G., MARTINEZ-SUAREZ, J.V, AGUADO-URDA, M., LOPEZ ALONSO, V, Springer Briefs in Food, Health and Nutrition, 12, 2012, p. 1

18.DESHMUKH, R.A, J OSHI, K., BHAND, S., ROY, U., Microbiologyopen, 5, no. 6, 2016, p. 901

19. LAZCKA, O., DEL CAMPO, F.J ., MUNOZ, F.X., Biosens. Bioelectron., 22, 2006, p. 1205

20. CLARISSA, L., NATHANIEL, C.C., CARL, A.A., Sensors, 9, 2009, p. 3713

21. MOTHERSHED, E.A., WHITNEY, A.M., Clin. Chim. Acta, 363, 2006, p. 206

22. LEE, J.Y., DEININGER, R.A., American Laboratory News Edition, 33,2001, p. 24

23. SCHREPPEL, C.K, TANGORRA, P.A, HARKINS, K.R., HARRIGAN, K. FREDERICKSEN, D.W., W QTC Proceedings, AWWA, 2002

24. SAMENDRA, P.S., MASAAKI, K., CHARLES, P.G. IAN L.P., Biosensors J ournal, 3, no. 1-1000109, 2014, p.1

25. HELMI, K., BARTHOD, F., MEHEUT, G., HENRY, A., POTY, F., LAURENT F., CHARNI-BEN-TABASSI, N., J. Water Health, 13.1, 2015, p. 34
26.VELUSAMY, V., ARSHAK, K., KOROSTYNSKA, O., OLIWA, K., ADLEY, C., Biotechnol. Adv., 28, 2010, p. 232

27.CHEONG, K.H., YI, D.K., LEE, J.G., PARK, J.M., KIM, M.J., EDEL, J.B., KO, C., Lab. Chip., 8, 2008, p. 810

28. LIU, R.H., YANG, J., LENIGK, R., BONANNO, J., GRODZINSKI, P., Anal. Chem., 76, 2004, p. 1824

29. LAW, W.S., TAY, E.T., FENG, H., YU, L., ZHAO, J.H., LI, S.F, J. Sep. Sci., 30, 2007, p. 1446.

30. YANG, L., LI, Y., Analyst, 131, 2006, p. 394

31. NAJA, G., BOUVRETTE, P., HRAPOVICH, S., LIU, Y., LUONG, J.H.T., J. Raman Spectrosc., 38, 2007, p.1383

32. SCHNEIDER, K., LAM, M., PARISH, M., Handbook of food science, technology and engineering, 4, Taylor \& Francis Group, HUI Y.H., SHERKAT, F. (Ed.), Chapter 186, 2005, p. 583

33. ***http://www.ni.com/vision/software

34. ***National Instruments, IMAQ Vision for labWindow/CVI User Manual, Part Number 371266A-01, p.86

35. SENTHILKUMARAN, N., KIRUBAKARAN, C., Int. J. Comput. Sci. Inf. Technol., 5, no. 2, 2014, p. 2173

36.***http://zone.ni.com/reference/en-XX/help/372916L-01/ nivisionconcepts/thresholding/

37.*** National Instruments, IMAQ Vision Concepts manual, Part Number 322916A, 2000, p. 140

Manuscript received: 21.03 .2018 